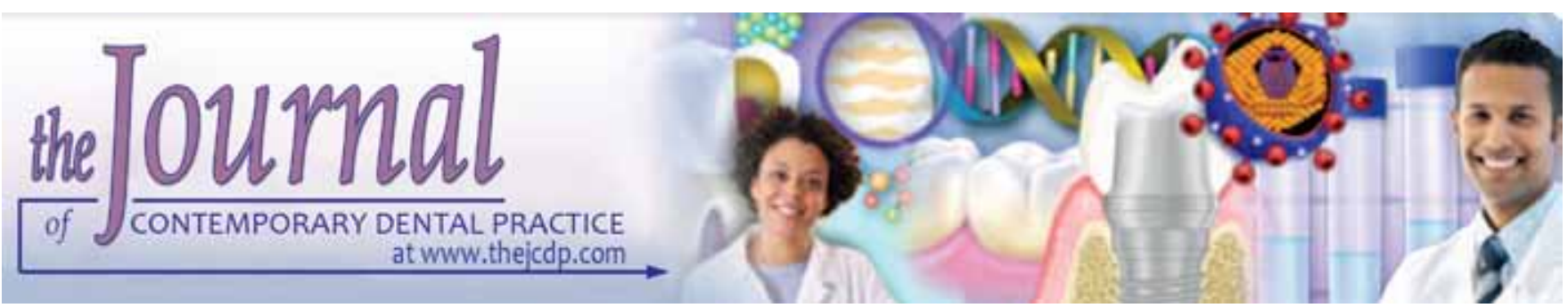

\title{
Cone-beam Computed Tomography Evaluation of Root Canal Preparation using Various Rotary Instruments: An in vitro Study
}

${ }^{1}$ Suhashini Ramanathan, ${ }^{2}$ Pradeep Solete

\begin{abstract}
Aim: To evaluate the remaining dentin thickness of teeth after cleaning and shaping the root canal using three rotary instrumentation technique using cone-beam computed tomography (CBCT).
\end{abstract}

Materials and methods: This in vitro study is being done with 30 premolar samples with $20^{\prime}$ curvature. The study is divided into three groups a CBCT was taken to measure the shortest distance from the root canal outline to the closest adjacent root surface was measured at each level from the cementoenamel junction (CEJ) $(1,3,5$ and $7 \mathrm{~mm}$ ) before and after root canal instrumentation. The purpose of this study was to compare the effects of different instruments used to prepare curved root canals on the remaining cervical dentin thickness and total amount of dentin removed from root canals during instrumentation by using multi-slice CBCT. The remaining dentin thickness is very much necessary for the success rate of root canal treatment. However, this study helps to prove that a conservative preparation with a sound remaining dentin thickness is much more advisable.

Result: It was observed that there was a significant difference at 1 and $3 \mathrm{~mm}(p<0.05)$ and at 5 and $7 \mathrm{~mm}$ there was no significant difference $(p>0.05)$. Mtwo has removed less amount dentin when compared to ProTaper Universal and ProTaper Next system at 1 and $3 \mathrm{~mm}$.

Conclusion: Under the conditions of the study, we concluded that ProTaper Universal and ProTaper Next should be used judiciously, as it causes higher thinning of root dentin of the root when compared with Mtwo.

\footnotetext{
1,2Department of Conservative Dentistry and Endodontics Saveetha Dental College and Hospital, Chennai, Tamil Nadu India

Corresponding Author: Suhashini Ramanathan, Undergraduate Student, Department of Conservative Dentistry and Endodontics, Saveetha Dental College and Hospital, Chennai Tamil Nadu, India, e-mail: suhasnathan@yahoo.in
}

Keywords: Cone-beam computed tomography, Dentin thickness, Heroshaper rotary instrumentation, iRace, Nickeltitanium, ProTaper.

How to cite this article: Ramanathan S, Solete P. Cone-beam Computed Tomography Evaluation of Root Canal Preparation using Various Rotary Instruments: An in vitro Study. J Contemp Dent Pract 2015;16(11):869-872.

Source of support: Nil

Conflict of interest: None

\section{INTRODUCTION}

The cleaning and shaping of root canal space is one of the most important and fundamental aspects of endodontic therapy. Better endodontic outcomes are achieved when preserving the original canal shape by using less invasive methods. ${ }^{1}$ Cleaning and shaping remove all the tissue debris and inner layers of root canal dentin regardless of the instrumentation technique. The thickness of the remaining dentin following intra-radicular procedures correlates to fracture resistance of the root. ${ }^{2}$

Regardless of the instrumentation technique, cleaning and shaping procedures invariably lead to dentin removal from the canal walls but flaring the canals excessively decreases the dentin thickness resulting the reduction of remaining dentin thickness, thus increases the possibility of vertical root fracture. Several studies have shown that instrumentation with automated devices using rotary nickel-titanium (NiTi) instruments with various tapers led to promising results; i.e. less straightening or decentralization of the canal, and a rounder canal preparation even in severely curved root canals. ${ }^{3-7}$ Deviation from the original curvature can lead to excessive or inappropriate dentin removal, straightening of the canal and creation of ledge in the dentinal wall, a biomechanical defect known as elbow, which forms the coronal to the elliptical-shaped apical seal, canals with 
hourglass appearance in cross section, which requires stripping and over-preparation that weakens the tooth, resulting in fracture of the root. Thus, the remaining dentin thickness is important because the amount of dentin remaining enables the endodontically treated teeth to resist from fracture. ${ }^{8}$

Recently, a nondestructive technology has been advocated for pre- and post-instrumentation evaluation of canal. Cone-beam computed tomography can render cross-sectional (cut plane) and three-dimensional (3D) images that are highly accurate and quantifiable. In this study, we can evaluate the remaining dentin thickness of root canal before and after instrumentation. The rotary instrument that were used in this study, are-ProTaper, ProTaper Next and Mtwo.

ProTaper instruments (Dentsply Maillefer, Ballagigues, Switzerland) features a variable taper over the length of its cutting blades and also a convex triangular cross section, a changing helical angle and pitch over the cutting blades and a noncutting, modified guiding tip. It consists of three shaping and finishing instruments. ${ }^{9}$

ProTaper Next has a patented, off-centred, rectangular cross section giving the files a unique, snake-like swaggering movement. This improved action creates an enlarged space for debris removal, optimizes the canal tracking and reduces binding. It also helps to tackle nearly all of the treatable root canals, even the complex ones.

The Mtwo endodontic instruments (VDW, Munich, Germany) are a new generation of NiTi rotary instruments recently introduced in the European market. The standard set for this system includes four instruments with variable tip sizes ranging from \#10 to \#25, and tapers ranging from 0.04 to 0.06 . The cross section of Mtwo is an 'italic $S^{\prime}$ with two cutting blades. ${ }^{10}$

\section{AIM AND OBJECTIVE}

The aim of the study is to compare remaining dentin thickness at 1, 3, 5 and $7 \mathrm{~mm}$ from the cementoenamel junction (CEJ) before and after instrumentation with Mtwo, ProTaper Universal, ProTaper Next by using CBCT.

\section{MATERIALS AND METHODS}

Thirty untreated human mandibular premolars with mature apices and intact roots were used in this experimental study. The curvature of the teeth was less than $20^{\circ}$ described by Scheider are selected. Teeth were stored in $10 \%$ buffered formalin solution. A preoperative CBCT were taken and the RDT was measured $(1,3,5$ and $7 \mathrm{~mm}$ respectively from the $\mathrm{CEJ}$ ) into the canal in axial sections, following which standard endodontic access cavity was prepared. A patency K-file size \#15 (Dentsply, Maillefer,
Switzerland) was passively introduced into the canals until it became visible from apical foramen. Working length was established at $0.5 \mathrm{~mm}$ short of this point. Occlusal rims are prepared using modeling wax with the size equivalent to the bite plane of CBCT. To avoid confusion the occlusal rims were marked with marker. The samples were divided into 10 for each rotary instrument group. Seventeen percentage EDTA was used during instrumentation.

Group I: Instrumented using Mtwo

Group II: Instrumented using ProTaper

Group III: Instrumented using ProTaper Next

All the instruments and technique of usage were according to the manufacturing instructions. After instrumentation all samples were irrigated with a final rinse of saline and the postoperative CBCT was taken maintaining the same position and recorded the values are noted in the computer. All the values were noted in excel spreadsheet and the statistics were performed using Statistical Package for the Social Sciences (SPSS) 20 software.

\section{RESULTS}

Table 1 result shows that there is a significant difference seen at 1 and $3 \mathrm{~mm}$, p-values are 0.043 and 0.048 respectively among three groups. No significant difference was seen at 5 and $7 \mathrm{~mm}$. Hence, post hoc Tukey was performed to evaluate the significant difference at 1 and $3 \mathrm{~mm}$.

Intergroup comparison was done at $1 \mathrm{~mm}$ and $3 \mathrm{~mm}$ using Post hoc Tukey, group I (Mtwo) removed less dentin at 1 and $3 \mathrm{~mm}$ when compared to groups II and III and its statistically significant (Table 2). At 5 and $7 \mathrm{~mm}$

Table 1: Mean and standard deviation at 3 and $7 \mathrm{~mm}$ for three groups

\begin{tabular}{lllll}
\hline & Group I & Group II & Group III & p-value \\
\hline $\begin{array}{l}\text { Difference at } \\
1 \mathrm{~mm}\end{array}$ & $0.32 \pm 0.05$ & $0.78 \pm 0.15$ & $0.67 \pm 0.08$ & 0.043 \\
$\begin{array}{l}\text { Difference at } \\
3 \mathrm{~mm}\end{array}$ & $0.28 \pm 0.07$ & $0.69 \pm 0.08$ & $0.62 \pm 0.05$ & 0.048 \\
$\begin{array}{l}\text { Difference at } \\
5 \mathrm{~mm}\end{array}$ & $0.23 \pm 0.08$ & $0.56 \pm 0.09$ & $0.52 \pm 0.07$ & 0.068 \\
$\begin{array}{l}\text { Difference at } \\
7 \mathrm{~mm}\end{array}$ & $0.19 \pm 0.05$ & $0.43 \pm 0.07$ & $0.40 \pm 0.05$ & 0.072 \\
\hline
\end{tabular}

Table 2: Intergroup mean difference and significant value at 1 and $3 \mathrm{~mm}$

\begin{tabular}{llcl}
\hline & Intergroup & Mean difference & $p$-value $(<0.05)$ \\
\hline $1 \mathrm{~mm}$ & 1 vs 2 & 0.06 & 0.045 \\
& 1 vs 3 & 0.04 & 0.048 \\
3 & 2 vs 3 & -0.01 & 0.78 \\
& 1 vs 2 & 0.07 & 0.041 \\
& 1 vs 3 & 0.05 & 0.045 \\
& 2 vs 3 & -0.02 & 0.738 \\
\hline
\end{tabular}


Mtwo performed good when compared to other rotary system but which is not statistically significant.

\section{DISCUSSION}

In the present study, we have used CBCT to evaluate the remaining root dentin thickness. There are number of methodologies to evaluate different instrumentation techniques in preparing root canals including plastic blocks, ${ }^{11}$ radiographic techniques, ${ }^{12}$ histological sections, ${ }^{13}$ serial sectioning, scanning electron microscope ${ }^{14}$ and silicone impressions of instrumented canals. ${ }^{15}$

One of the latest innovations in the industrial and medical field is the use of CBCT for study purpose; this scientific tool could develop a potential in endodontic research as well. Which provide a practical and nondestructive technique for assessment of remaining root dentin thickness before and after shaping according to Gluskin et al 2001. ${ }^{16}$

Step-back and/or crown down strategies for shaping have been the established paradigm for creating tapered shapes during the last 20 years. ${ }^{17}$ The advent of predefined tapered shapes to root canals was given great impetus with the introduction of NiTi instruments which has good shape memory, highly flexible alloy has allowed innovations in taper and flute design that had been impossible with stainless steel instruments. In addition, increased taper combined with NiTi alloy allowed more predictable use of rotary methods to provide consistent canal shape. ${ }^{18}$

Even experienced clinician encounters an increased potential for structural loss during shaping. Adequate taper shape provides enough space for irrigants that are important to complete the canal cleaning and allows the placement of an effective root filling ${ }^{19}$ and the quality of root canal sealing. But at the same time removal of excess root dentin may lead to root fracture.

The results of our study showed that there is some significant difference in remaining root canal dentin thickness at 1 and $3 \mathrm{~mm}$ respectively. The differences in the dentin thickness at $1 \mathrm{~mm}$ for each groups (Mtwo-0.32 \pm 0.05 , ProTaper $-0.78 \pm 0.15$, ProTaper Next-0.67 \pm 0.08 ) for $3 \mathrm{~mm}$ (Mtwo-0.28 \pm 0.07 , ProTaper-0.69 \pm 0.08 , ProTaper Next- $0.62 \pm 0.05$ ) respectively. The result obtained is due to the progressive taper of the group 2 and group 3 instruments, which eventually removed more dentin at 1 and $3 \mathrm{~mm}$ level from CEJ toward apex. The Mtwo is a positive rake angle, uniform taper design, $\mathrm{S}$ shaped cross section, removes less dentin and maintain the canal anatomy. Group 2 showed higher removal of dentin which can be mainly attributed to progressive taper along the cutting surface in combination with the sharp cutting edges. Progressively tapered design along with triangular convex cross sectional design could have led to aggressive cutting according to Ruddle et al. ${ }^{20}$ The
ProTaper Next having uniform taper unlike ProTaper universal system, the cutting is rectangular in cross section of which only two sides touches the root canal. At 5 and $7 \mathrm{~mm}$, there is some significant difference seen in Mtwo when compared to other two systems but, it is not statistically significant.

The pericervical dentin, the dentin near the alveolar crest, it is irreplaceable. This critical zone, roughly $4 \mathrm{~mm}$ above the crestal bone and extending $4 \mathrm{~mm}$ apical to the crestal bone, is important for three reasons: ferrule, fracturing, and dentin tubule orifice proximity from inside to out. Long-term retention of the tooth and resistance to fracturing are directly related to the amount of residual tooth structure. The more dentin is kept, the longer the tooth is kept. ${ }^{21}$

\section{CONCLUSION}

The study shows that the Mtwo resulted in conserving more dentin compared to the other system at all sections but it is significant only at 1 and $3 \mathrm{~mm}$. Research should continue to further improve instrument design, preparation techniques, and methodologies that are used to evaluate the action of endodontic instruments inside the root canal, aiming at solving the problems inherent to shaping of canals an important and difficult phase of the endodontic therapy. The ProTaper universal and ProTaper Next removed almost same amount of root dentin.

\section{REFERENCES}

1. Peters OA. Current challenges and concepts in the preparation of root canal systems: a review. J Endod 2004;30:559-567.

2. Vallabhaneni S, More GR, Gogineni R. Single file endodontics. Ind J Dent Adv 2012;4:822.

3. Chen JL, Messer HH. A comparison of stainless steel hand and rotary nickel-titanium instrumentation using a silicone impression technique. Aust Dent J 2002;47:12-20.

4. Kum KY, Spängberg L, Cha BY, Il-Young J, Seung-Jong L, Chan-Young L. Shaping ability of three ProFile rotary instrumentation techniques in simulated resin root canals. J Endod 2000;26:719-723.

5. Thompson SA, Dummer PM. Shaping ability of ProFile.04 Taper Series 29 rotary nickel-titanium instruments in simulated root canals-Part 2. Int Endod J 1997;30:8-15.

6. Garip Y, Günday M. The use of computed tomography when comparing nickel-titanium and stainless steel files during preparation of simulated curved canals. Int Endod J 2001;34:452-457.

7. Glossen CR, Haller RH, Dove SB, Del Rio CE. A comparison of root canal preparations using NiTi hand, NiTi engine-driven, and K-Flex endodontic instruments. J Endod 1995;21:146-151.

8. Guelzow A, Stamm O, Martus P, Kielbassa AM. Comparitive study of six rotary nickel-titanium systems and hand instrumentation for root canal preparation. Int Endod J 2005; 38(10):743-752.

9. Kaptan F, Sert S, Kayahan B, Haznedaroglu F, Tanalp J, Bayırli G. Comparative evaluation of the preparation efficacies of HERO Shaper and Nitiflex root canal instruments in curved 
root canals. Oral Surg Oral Med Oral Pathol Oral Radiol Endod 2005;100:636-642.

10. Malagino VA, Grande NM, Plotino G, Somma F. Italy. The Mtwo NiTi rotary system for root canal preparation. Industry_grande Roots 65-70.

11. Weine FS, Kelly RF, Lio PJ. The effect of preparation procedures on original canal shape and on apical foramen shape. J Endod 1975;1:255-262.

12. Walton RE. Histologic evaluation of different methods of enlarging the pulp canal space. J Endod 1976;2:304-311.

13. Mizrahi SJ, Tucker JW, Seltzer S. A scanning electron microscopic study of the efficacy of various endodontic instruments. J Endod 1975;1:324-333.

14. Seidler B. Root canal fillings: an evaluation and method. J Am Dent Assoc 1956;53:567-576.

15. Bramante CM, Berbert A, Borges RP. A methodology for evaluation of root canal instrumentation. J Endod 1987;13:243-245.
16. Gluskin AH, Brown DC, Buchanan LS. A reconstructed computerized tomographic comparison of NiTi rotary GT files versus traditional instruments in canals shaped by novice operators. Int Endod J 2001;34:476-484.

17. Schilder H. Cleaning and shaping the root canal. Dent Clin North Am 1974;18:269-296.

18. Short JA, Morgan LA, Baumgartner JC. A comparison of canal centering ability of four instrumentation techniques. J Endod 1997;23:503-507.

19. Park H. A comparison of greater taper files, profiles, and stainless steel files to shapen curved root canals. Oral Surg Oral Med Oral Pathol Oral Radiol Endod 2001;9:715-718.

20. Ruddle CJ. Current concepts for preparing the root canal system. Dentistry Today 2012. p. 76-83.

21. Clark D, Khademi J. Dental Clinics of North America 2010. p. 249-273. 